\title{
PROBLEMATIZANDO A GARANTIA DOS DIREITOS QUILOMBOLAS: ARENAS DE NEGOCIAÇÃO E AÇÕES DO ESTADO
}

\section{PROBLEMATIZING THE GUARANTEE OF "QUILOMBOLA" RIGHTS: NEGOTIATION ARENAS AND STATE ACTIONS}

Vânia Fialho ${ }^{1}$

\begin{abstract}
RESUMO
O período de democratização do Estado brasileiro foi marcado pela ação de movimentos sociais que colocou no cenário político o protagonismo de segmentos sociais emergentes, dentre eles as comunidades quilombolas. A Constituição de 1988 representa significativa mudança de paradigma em relação ao reconhecimento de novos direitos e novos sujeitos de direito no contexto brasileiro. Enfrentada com certa resistência no plano jurídico e, muitas vezes, até acadêmico, a categoria de povos e comunidades tradicionais congrega um conjunto de demandas mobilizadas organizadamente que recebem diferentes denominações, como é o caso das comunidades quilombolas. São estratégias que emergem em meio aos movimentos sociais no campo vinculadas à designação dos sujeitos de ação que não aparecem mais atreladas à conotação política própria do termo camponês. No entanto, sua implementação tem trazido grandes desafios, considerando a tradição agrária brasileira e a sua estrutura fundiária, que acabaram por definir as relações entre diferentes segmentos da sociedade e grupos de controle do poder que exerceram sua hegemonia com base na violência física e simbólica. Este trabalho discute o contexto em que a mobilização quilombola se desenvolveu e analisa diferentes fontes de dados sobre as mesmas nos estados de Alagoas, Pernambuco e Sergipe. No cerne do trabalho está a discussão sobre a tensão entre dois modelos para compreender o contexto de garantias constitucionais das comunidades quilombolas: o "idealístico" ou "sistêmico" e o que parte da ideia de "arena", enfatizando o processo político e a necessidade de múltiplas negociações entre grupo de participantes.
\end{abstract}

Palavras-chave: Quilombos. Direitos Constitucionais. Povos e Comunidades Tradicionais. Política.

${ }^{1}$ Doutora em Sociologia, UPE/PPGA-UFPE. E-mail: vania.fialho@upe.br. 


\begin{abstract}
The Brazilian State democratization period was marked by the action of social movements that have put the leading role of emerging social sectors, such as "Quilombola" communities, within the political scene. The 1988 Constitution represents a significant paradigm change in the acknowledgment of new rights and subjects of rights within the Brazilian context. The categories of traditional people and communities that face some resistance in the juridical level and, sometimes, even in the academic level, gather a set of organizationally mobilized demands that have different names, such as the case of "Quilombola" communities. There are strategies that rise among the social movements in the field that are bound to the so-called subjects of action, who are not linked to the political meaning particularly given to the word 'peasant'. However, their implementation brings great challenges that ended up defining the relationship between different sectors of society and power control groups. These sectors and groups have set their domination based on physical and symbolic violence, if one takes into account the Brazilian agricultural tradition. The current study addresses the context wherein the "Quilombola" mobilization was developed, as well as analyzes different sources of data about these sectors and groups in the states of Alagoas, Pernambuco and Sergipe. The very core of the current study holds the discussion about the tension between the two models used to understand the context of constitutional guarantees to Quilombola communities: the "idealistic" or "systemic" and the one that begins with the sense of "arena" through the emphasis given to the political process and through the need of multiple negotiations among the participating groups.
\end{abstract}

Keywords: Quilombola Community. Constitutional Rights. Traditional People and Communities. Policy. 
Cada movimento [social] tem um significado, o movimento é como o órgão de sentido, cada um serve pra alguma coisa, todos têm fundamento, todos têm valor, todos têm necessidade de ser e todos têm validade, e nenhum é melhor do que o outro, porque juntos que formam um corpo, mas cada um serve pra alguma coisa, ele não é o mesmo um, mesmo um não, um é diferente do outro. Nice Aires (Mulher, quilombola e extrativista da floresta) (AIRES, 2016, p. 101)

O objetivo deste artigo é discutir os desafios que enfrentamos no momento em que se coloca em questão os direitos de povos e comunidades denominados tradicionais. Contraditoriamente, por um lado, e sintomaticamente, por outro, a presença de comunidades tradicionais passou a representar temática constante nas definições do Estado: políticas públicas específicas, espaços de negociação (institucionalizados, como em conselhos), estrutura fundiária, reconhecimento de sujeitos políticos, dentre outros. O fato é que a necessidade formal de identificação de comunidades tradicionais ou "especiais" e a consideração das mesmas no projeto de sociedade brasileira tem explicitado conflitos de interesses e tem dado visibilidade às tensões no contexto rural brasileiro, o que se apresenta de maneira aguçada neste momento de complexa instabilidade política e estrutural da sociedade brasileira, quando observamos indicativos de verdadeiro desmonte dos direitos conquistados nas últimas duas décadas.

Para provocar essa reflexão, foi escolhida uma vertente desse contexto: a articulação da mobilização política de grupos sociais que acionam a identidade étnica na afirmação do seu espaço na esfera de negociação com o Estado brasileiro, como é o caso das comunidades quilombolas. A proposta é uma digressão que articula elementos da antropologia aos da ciência política, buscando caminho que se distancia de uma perspectiva culturalista.

As reformas constitucionais na América Latina, que ganharam fôlego a partir da década de 80 passada, trouxeram a possibilidade de pensarmos em outras lógicas que se desdobram em novas normatividades, cuja palavra central é a pluralidade. A relação com o Estado tem se reconfigurado, principalmente, devido aos novos lugares assumidos pelos "novos" movimentos sociais que têm objetivado seu potencial identitário com base em diferentes demandas, como as específicas de grupos étnicos e raciais, de minorias sexuais, de defesa do meio 
ambiente, dentre outros. A categoria de "povos e comunidades tradicionais" tem se destacado e aglutinado boa parte dos movimentos acima citados ao colocarem como pauta comum a defesa de territórios e do uso tradicional dos recursos naturais.

Instrumentos normativos regulatórios e recomendatórios colocam a necessidade de consulta aos povos e comunidades tradicionais sobre os seus interesses nas áreas a serem ocupadas e/ou atingidas; e é exatamente essa situação de tensão que tem enfatizado a necessidade de atentarmos para as dinâmicas territoriais que se configuram em momentos históricos diferentes.

Na atualidade, como aponta Vianna (2010, p.112), vemos que

as organizações dos povos e comunidades tradicionais encaminharam demandas, parcialmente atendidas por agências governamentais em políticas agrárias, sociais e ambientais, que resultaram na edição de leis e na instituição de instrumentos normativos que garantem o acesso a terras de diversas formas: como propriedades privadas individuais (reforma agrária e regularização fundiária), propriedades privadas comunitárias (reforma agrária e política de regularização de territórios quilombolas), terras públicas em que comunidades têm posse permanente (política indigenista e política ambiental).

Outras formas de conformação territorial também ganharam expressão sem que estejam diretamente relacionadas às demandas citadas, como as áreas reservadas, as unidades de conservação de proteção integral; porém, estas acabam compondo muitas das situações em que os pleitos das comunidades tradicionais se colocam, pois, com frequência, há sobreposição de interesses e de figuras jurídicas.

Enfrentada com certa resistência no plano jurídico e muitas vezes, até acadêmico, a categoria de povos e comunidades tradicionais congrega um conjunto de demandas mobilizadas organizadamente em núcleos que recebem diferentes denominações. Almeida (2011) aponta, por exemplo, a força mobilizatória de "comissões" (de "atingidos por barragens"), "conselhos" (de seringueiros), "associações" (de garimpeiros e de "assentados") e "comunidades negras rurais" ou "comunidades remanescentes de quilombos" e "comunidades" de resistência indígena. São estratégias que emergem em meio aos movimentos sociais no campo vinculadas à designação dos sujeitos de 
ação que não aparecem mais atreladas à conotação política própria do termo camponês.

De acordo com o mesmo autor, trata-se da politização dos termos de uso local e referidos a realidades localizadas;

[...] seu uso cotidiano e difuso não é visto como se opondo aos movimentos classistas, antes parece ser considerado como fator de educação política[...]. Cinde-se com o monopólio político do significado dos termos camponês e trabalhador rural, que até então eram utilizados com prevalência por partidos políticos, movimento sindical dos trabalhadores rurais e entidades confessionais (ALMEIDA, 2011, p. 17).

Constituem unidades de mobilização, organismos legítimos para compor mesas de negociação na tentativa de resolução de conflitos.

As comunidades quilombolas se colocam como uma dessas categorias que se articulam como unidades de enfrentamento, e se mobilizam, no período pós-1988, a partir da ideia de resistência em que o fator étnico é publicizado e tornado um dos critérios político-organizativo (ALMEIDA, 2011, p. 58).

Várias categorias relativas à origem, à raça, à etnia foram computadas durante o transcorrer da nossa história, sob a forma de uma única denominação, ora de índio, ora de camponês, ocorrendo o mesmo com a categoria negro, escravo e até branco, o que dificultou a utilização dos documentos oficiais para tentar recompor a ocupação da região Nordeste, que é nosso foco.

O ideal de liberdade associado ao estigma de estar à margem de uma sociedade, provocaram em muitos momentos, no solo nordestino, a cooperação, principalmente, entre negros e índios, que deram conformação a territórios em que esta aliança representava a existência de uma organização à parte, fora do controle colonial.

Tais presenças e alianças foram ofuscadas durante séculos com a projeção de um ambiente pretensiosamente homogêneo, que só começa a ser desvelado, a partir de 1988, com o reconhecimento oficial, por parte do Estado, do caráter plural que reveste a sociedade brasileira. Este tem se configurado com um rico processo em curso de afirmação de uma 
identidade étnica que demonstra quão complexa é a constituição do que é genericamente denominado como "rural" ou "camponês".

Sem dúvida, há a necessidade de considerar a injustiça socioeconômica enraizada no modelo social de representação, interpretação e comunicação, mas esta precisa ser conjugada com questões de classe, gênero e etnia; o que nos leva a olhar para o meio rural a partir a ideia de diferença, identidade e cultura que seriam identificadas por Fraser (1997) como fundamentais para a contemporaneidade ocidental, a fim de contemplar as três dimensões presentes na realidade: a material, a cultural e a política.

A partir desta necessidade, podemos perceber uma ruralidade marcada por duas dinâmicas, que, embora tratadas analiticamente de forma distinta, estão profundamente relacionadas: as dinâmicas de mobilização e as dinâmicas territoriais. A fixidez dos registros cartográficos, censos, cadastros liderados por agências governamentais, dá pouca possibilidade da incorporação dessas dinâmicas; seu caráter é geralmente dado como de longo prazo, nunca situacional, como os processos sociais assim requerem.

Entendemos as primeiras das dinâmicas citadas como forma de articulação e politização de unidades de mobilização ${ }^{2}$, que se estruturam a partir da ideia de redes e acabam por conformar categorias a serem reconhecidas pelo poder estatal. As segundas se referem à projeção dessas mobilizações no espaço que promovem um redesenhar constante de limites de territórios resultante dos jogos e negociações que objetivam afirmar e reconhecer a existência de grupos sociais definidos por diferentes critérios de coesão e solidariedade.

Para Piraux (2009, p. 32), conforme já destacamos em trabalho anterior (FIALHO, 2011), as dinâmicas territoriais podem ser definidas como a resultante entre os interesses e projetos coletivos dos atores sociais, assim como as suas evoluções e traduções em um espaço dado. Nessa definição, os atores são considerados como grupos e segmentos diferenciados da sociedade civil e do Estado, os quais constituem

${ }^{2}$ Como unidades de mobilização, Almeida (2006) se refere à aglutinação de interesses específicos de grupos sociais não necessariamente homogêneos, que são aproximados circunstancialmente pelo poder nivelador da intervenção do Estado, cujas ações reivindicatórias de desdobram em movimentos sociais. 
conjuntos relativamente homogêneos segundo sua posição na vida sociocultural e econômica e, por sua prática coletiva, constroem identidades, interesses e visões de mundo convergentes. Assim, o movimento de reconhecimento de identidades diferenciadas, como aquelas agrupadas pela categoria de populações tradicionais, ou mais especificamente no caso em questão, as comunidades quilombolas, tem provocado tanto uma reflexão sobre a identidade nacional, como a forma de constituir novos direitos.

De alguma maneira, temos, a partir de 1988, a identificação de diferentes populações, o que não quer dizer o reconhecimento dos sujeitos que as compõem como cidadãos. Chatterjee define com clareza essa distinção:

Cidadãos habitam o domínio da teoria, populações, o domínio das políticas públicas. Diferentemente do conceito de cidadão, o conceito de população é totalmente descritivo e empírico; não traz nenhuma carga normativa. Populações são identificáveis, classificáveis e descritíveis por critérios empíricos ou comportamentais, e são abertas a técnicas estatísticas tais como censos e pesquisas amostrais. Diferentemente do conceito de cidadão, que carrega uma conotação ética de participação na soberania do Estado, o conceito de população torna acessível aos funcionários governamentais um conjunto de instrumentos racionalmente manipuláveis para alcançar largos setores dos habitantes de um país enquanto alvo de suas "políticas", - políticas econômicas, políticas administrativas, justiça e mesmo mobilização política (CHATTERJEE, 2013 p. 107).

O autor destaca que tudo isso tornou a governança uma questão menos do político e mais das políticas administrativas, um trabalho de peritos mais que de representantes políticos.

Eis aqui o "nó" da discussão proposta. Enfrentamentos foram feitos, garantias normativas passaram a existir, mas há um vácuo entre o reconhecimento formal e a participação dos movimentos quilombolas. Há necessidade de enfrentarmos o que Chatterjee nos coloca como sociedade política. Esta ideia identifica algo novo na maneira como as autoridades governamentais começaram a negociar com grupos da população. "Tais relações já não se encaixavam na velha forma patrãocliente entre notáveis locais e seus protégées, nem equivalia a um 
despachante político que faz as coisas acontecerem numa repartição de governo em nome de uma comunidade local." (CHATTERJEE 2013).

A relação entre agentes sociais e a estrutura, tema clássico para teoria sociológica, é situada por Ufford (1997) a partir de dois modelos. O primeiro, "idealístico" ou "sistêmico", enfatiza o aspecto sistêmico das relações sociais, como se estivessem livres de contradições. Geralmente, esse modelo reflete os interesses dos que são responsáveis pela implementação de projetos, promovendo uma imagem de eficiência e maneabilidade, de coerência argumentativa e de integração entre os diferentes níveis organizacionais e geralmente sugere que as causas de possíveis falhas são oriundas de fora do coerente e integrado sistema administrativo. O segundo modelo parte da ideia de "arena", já ressaltado anteriormente, para enfatizar o processo político não como um todo integrado, mas como uma série de múltiplas negociações entre grupo de participantes - que pode se dar dentro de uma mesma agência, assim como entre diferentes níveis de organização, como as agências financiadoras, as receptoras, os técnicos e funcionários dos projetos locais e a própria população local, que defendem diferentes visões e interesses (UFFORD, 1997, p. 138-139).

Nossa sugestão é que as dificuldades que temos no trato da garantia dos direitos das comunidades quilombolas se dá pelo fato da constituição brasileira de 1988 estar situada no primeiro ciclo de reformas constitucionais latinoamericanas (FAJARDO, 2009), que, apesar de inspirada pelos princípios de emergência do multiculturalismo e pelo direito à diversidade cultural, não aprofunda sua efetivação.

\section{Ordem, desordem e multivocalidade}

De categoria que parecia desordenar a lógica tradicional da sociedade brasileira, as comunidades quilombolas vão se conformando como unidades de mobilização importantes no contexto político. 
Tomando como base os dados da Fundação Cultural Palmares sobre as comunidades certificadas $^{3}$, temos a partir de 2003, quando é definido o procedimento para identificação, reconhecimento, delimitação, demarcação e titulação das terras ocupadas por remanescentes das comunidades dos quilombos (decreto 4887, de 20. 11.2003), os seguintes dados para os estados de Alagoas, Pernambuco e Sergipe:

\section{Quadro 1: Comunidades Quilombolas Certificadas nos estados de Alagoas, Pernambuco e Sergipe, de 2004 a 2012}

\begin{tabular}{|c|c|c|c|}
\hline \multirow{2}{*}{ ANO } & \multicolumn{4}{|c|}{ COMUNIDADES QUILOMBOLAS CERTIFICADAS } \\
\cline { 2 - 4 } & ALAGOAS & PERNAMBUCO & SERGIPE \\
\hline 2004 & & 05 & 02 \\
\hline 2005 & 10 & 45 & 04 \\
\hline 2006 & 08 & 11 & 08 \\
\hline 2007 & 03 & 19 & 01 \\
\hline 2008 & 01 & 11 & 00 \\
\hline 2009 & 27 & 03 & 00 \\
\hline 2010 & 14 & 06 & 00 \\
\hline 2011 & 01 & 07 & 07 \\
\hline 2012 & 00 & 01 & 03 \\
\hline 2013 & 00 & 04 & 02 \\
\hline 2014 & 01 & 12 & 02 \\
\hline 2015 & 02 & 04 & 00 \\
\hline TOTAL & 67 & 128 & 27 \\
\hline
\end{tabular}

Fonte: Fundação Cultural Palmares, 2016.

A certificação é o primeiro passo, antes mesmo de aberto o processo de reconhecimento do território quilombola. A partir desses dados, temos uma estimativa de processos que, com frequência, desembocam em disputas de direitos, de terras. Tais certificações são demandadas por

\footnotetext{
${ }^{3}$ De acordo com o Art. $6^{\circ}$ da a Instrução Normativa, a cerificação é assim definida: Art. $6^{\circ}$. A caracterização dos remanescentes das comunidades de quilombos será atestada mediante auto definiçãa da comunidade. Parágrafo único. A auto definição da comunidade será certificada pela Fundação Cultural Palmares, mediante Certidão de Registro no Cadastro Geral de Remanescentes de Comunidades de Quilombos do referido órgão, nos termos do $\S 4^{\circ}$, do art. $3^{\circ}$, do Decreto ${ }^{\circ} 4.887$, de 20 de novembro de 2003.
} 
unidades de mobilização que assumem diferentes formas organizativas, na maioria das vezes, associações ${ }^{4}$.

As associações, mesmo sendo uma estratégia de articulação que possibilita seu reconhecimento formal pelo Estado, não representam exclusivamente uma forma organizativa quilombola.

No plano do concreto, do cotidiano, as categorias sociais se sobrepõem, se entrecruzam, assim como as próprias relações sociais. Há caso de associação que se define como quilombola, cujas pautas já se dão em torno da identidade étnica quilombola, outras, como associação de moradores, se articulam em torno de vizinhança, de demandas relacionadas a um espaço físico comum, outras, como associações de agricultores e de outras categorias de trabalhadores.

O que visualizamos como conformação da pluralidade da sociedade brasileira, é a multiplicidade de vozes que coloca a necessidade de reorganização do espaço agrário e a possibilidade de uma esfera de negociações que possibilite a ressonância dos diferentes argumentos evocados. As associações não têm o mesmo papel proposto pelos planejadores e executores de políticas, elas não estão à parte de todo processo histórico e organizacional de uma sociedade.

Se tomados como dados censitários, estatísticos, as categorias, os classificadores acionados mais parecem obstáculos ao processo de garantia de direitos. No caso das comunidades quilombolas, as unidades de mobilização que requerem a certificação, nem sempre apresentam de forma explícita o pertencimento étnico, envolvendo, muitas vezes referência ao espaço rural, colocando a disputa pela posse e domínio de terra. Geralmente,

[...] o fator étnico aparece como o componente que assegura a garantia de titulação definitiva das terras. E é a partir dele que o grupo social se reestrutura e consolida sua identidade coletiva em confrontação com seus tradicionais antagonistas, ou seja, os grandes "proprietários fundiários que usurparam suas terras. (ALMEIDA 2011).

\footnotetext{
${ }^{4}$ Conforme Portaria da Fundação Cultural Palmares N 98 de 26.11.2007.
} 
Tão importantes quanto os dados sobre as comunidades certificadas, que nos dão uma ideia sobre o potencial de mobilização pelo reconhecimento de direitos, dentre eles o territorial, são os dados cedidos pela Comissão Pastoral da Terra sobre os conflitos envolvendo comunidades quilombolas para os mesmos três estados da federação que destacamos acima. Entre os anos de 2000 e 2015, para os estados de Alagoas, Pernambuco e Sergipe, foram registrados, respectivamente, 6, 25 e 11 eventos caracterizados por expulsão de famílias de suas terras, ameaças de despejo, invasão dos territórios quilombolas, destruição de casas e de roças.

De forma significativa, o quadro e os dados dos conflitos, acima apresentados, constituem duas possibilidades de adentrar na questão quilombola; o primeiro permite visualizamos no âmbito administrativo um dos critérios a partir dos quais são contabilizadas as comunidades quilombolas. Articula-se com o aparato burocrático-normativo e com expertise técnica do Estado. Aproxima-se da visão sistêmica apresentada acima.

O segundo, refere-se ao mundo das dinâmicas e conflitos, apresenta o cômputo feito pela Comissão Pastoral da Terra ${ }^{5}$ sobre as "áreas quilombolas envolvidas em conflito por terra de 2000 a 2015 " e pode ser lida a partir da ideia de arena. Os conflitos constituem chaves de entendimento de grande importância para avaliarmos a eficácia de políticas e de ordenamento de direitos.

\section{As vozes em um exemplo}

Para ilustrar, vamos nos deter no relato do caso $^{6}$ da Comunidade Quilombola de Conceição das Crioulas ${ }^{7}$, situada no município de

\footnotetext{
${ }^{5}$ A CPT, Comissão Pastoral da Terra, é um órgão da Conferência Nacional dos Bispos do Brasil (CNBB), entidade voltada para a defesa dos Direitos Humanos e para os direitos dos trabalhadores e trabalhadoras da terra. Os dados são oriundos do Centro de Documentação Dom Tomás Balduino - CPT e foram gentilmente cedidos por Plácido Júnior, geógrafo e agente pastoral na $C P T$.

${ }^{6}$ Utilizo, para esse relato, os informes que escrevi para o Observatório Quilombola (FIALHO, 2004 e 2005)

${ }^{7}$ Tive a oportunidade de realizar o laudo antropológico que subsidiou o processo de reconhecimento territorial de Conceição das Crioulas em 1998.
} 
Salgueiro, em Pernambuco. Trata-se do segundo território quilombola reconhecido, titulado nesse estado da federação.

Situado numa região de histórica confluência de indígenas, negros e de toda a sorte de categorias que colocavam em risco a ordem colonial vigente durante séculos, o território de Conceição das Crioulas foi identificado em 1998 e titulado pela Fundação Cultural Palmares em 2000. Com 16.865 ha $^{8}$, seu território foi declarado de interesse social para fins de desapropriação através do Decreto Presidencial de 10/11/2009. Essa área quilombola é vizinha da Terra indígena Atikum, homologada por Decreto Presidencial em 1996.

A reorganização do espaço agrário da região, com a afirmação de uma forma legal de apropriação coletiva das terras quilombolas, se desenrolou, como seria de se esperar, carregada de problemas e conflitos. A indefinição do processo de regularização fundiária, só normatizado entre novembro de 2003 e março de 2004, proporcionou uma situação de insegurança, em que as ameaças por parte dos ocupantes das terras das Crioulas se intensificaram.

Os conflitos podiam ser percebidos desde o período de identificação do território quilombola, tendo como destaque naquele momento a dicotomia "quilombolas" versus "fazendeiros". Foram identificados 16 imóveis incidentes, porém, como o procedimento inicial não previa o levantamento fundiário, as informações eram imprecisas tanto em relação à dimensão dos imóveis quanto às suas porções que se sobrepõem às terras das Crioulas.

No entanto, o protagonismo político do núcleo de Conceição das Crioulas na região, que vinha sendo bem demarcado no plano políticopartidário, acabou por se refletir no contexto da regularização das terras quilombolas. Em 2000, Givânia Maria da Silva, liderança quilombola, se candidatou a uma vaga na Câmara de Vereadores do município de Salgueiro pelo Partido dos Trabalhadores (PT). Já Maria Irene Eruça, a Bebé, moradora do sítio Rodeador - um dos que integram a terra

\footnotetext{
${ }^{8}$ No levantamento fundiário realizado pelo INCRA, estão registradas duas áreas para o imóvel: a área registrada (16,865,0678 ha) e a área levantada $(17.845,0015$ ha). A diferença seria decorrente dos ajustes técnicos feitos pelo INCRA. (ANTUNES, 2016, p.286).
} 
quilombola -, se candidata pelo Partido da Frente Liberal (PFL). Apenas Givânia é eleita e reeleita em 2004.

A ação de Bebé centrava-se na ideia de fortalecer uma oposição ao projeto quilombola, defendendo a necessidade de extensão dos limites da Terra Atikum. Isso resultaria na incorporação de alguns dos sítios entre eles, o que ela mesma reside - situados na região limítrofe entre a Terra Indígena e a Terra de Remanescentes de Quilombos.

O destaque a Bebé se dá pelo fato desta vir liderando esse movimento de redefinição dos limites das terras Atikum e das Crioulas, com o fim de promover a mudança de categorias administrativas dos sítios denominados Massapê, Rodeador e Paus Brancos para 'aldeias indígenas'. Tal alteração propiciaria à população dessas localidades o mesmo tratamento dispensado aos índios. Portanto, sendo assim reconhecidos, os habitantes desses sítios passariam a ter acesso a serviços diferenciados de saúde e de educação.

É preciso ressaltar que os projetos políticos dessas duas personagens não se encontram atrelados diretamente aos anseios quilombolas e indígenas, nem devem ser assim entendidos. Givânia entra no cenário político a partir de sua articulação com o sindicato rural e a luta popular, opondo-se à estrutura conservadora de controle político e fundiário da região. Por outro lado, Bebé se vinculou ao PFL, cujos princípios estão vinculados à perpetuação do status quo e cujos representantes já constituíam oposição à Givânia.

Bebé já esteve articulada com o movimento quilombola e com o movimento de professores indígenas, mas, como foi afastada de ambos, procurou sua legitimação via Conselho Distrital de Saúde Indígena.

As tensões, por conseguinte, passaram por um processo de complexificação e se estruturaram a partir de diferentes perspectivas, mas que se encontram profundamente interligadas e podem ser identificadas por meio de: enfrentamentos entre quilombolas e fazendeiros; disputas político-partidárias nas eleições municipais; tentativas de acesso ao sistema de assistência nas áreas de educação e saúde e mecanismos de manipulação do sistema previdenciário. 
Na rearrumação que se deu na região com o reconhecimento oficial do território quilombola, as disputas acima citadas foram encobertas pela dicotomia: 'indígena' versus 'quilombola'. Nesse contexto, tais categorias identitárias devem ser entendidas como legalmente instituídas, às quais estão relacionadas prerrogativas específicas. E é exatamente no plano do direito e das competências administrativas que as contendas vão se instalar.

A preocupação com essas categorias não se dá apenas por uma questão teórica conceitual, Mas também porque reduzir a problemática fundiária vivenciada na região à disputa entre 'indígenas' e 'quilombolas' não possibilita o entendimento da mesma.

O mais grave é que esse tem sido o argumento recorrente utilizado pelos meios de comunicação e por instâncias diferenciadas do poder público para explicar os conflitos existentes. Vemos aí os tais classificadores baseados em princípios burocráticos acionados pelos poderes do Estado, sem considerar as dinâmicas sociais.

Para entendermos o contexto desses conflitos, hoje configurados, é necessário visualizar que a região que compreende os municípios de Floresta, Carnaubeira da Penha, Mirandiba, além de outros que compõem a região do semiárido pernambucano, foi palco de um intenso fluxo migratório entre os séculos XVII e XIX e dessa forma acabou por abrigar populações indígenas e negras que adentravam lá para fugir das frentes de expansão da cultura da cana e do gado.

A região da Serra do Umã, próxima às terras de Conceição das Crioulas, foi uma dessas áreas e há séculos abriga etnias diferentes, que têm mantido entre si relações de cooperação e parentesco e que hoje se identificam como os Atikum.

A Terra Indígena Atikum e a Terra de Conceição das Crioulas têm uma linha limítrofe em comum. Além da definição dos limites territoriais, do ponto de vista das políticas públicas, trata-se de definir as categorias jurídicas - de indígenas e quilombolas -, às quais são atribuídos direitos diferenciados.

Durante a realização da identificação do território quilombola de Conceição das Crioulas (1998), já se salientava que os limites entre a 
identidade indígena e quilombola nem sempre se mostravam tão claros. Trata-se de uma região, principalmente no trecho limítrofe entre as duas áreas, em que numa mesma família há membros que se identificam como indígenas e outros como quilombolas, e essa relação não vinha se apresentando como conflituosa.

Ao considerar as dimensões das áreas indígenas e quilombolas, os relatos indicam que as terras iam muito além do que hoje é demarcado. Mas, ao considerar o contexto atual da região, as definições dos limites territoriais correspondem aos espaços que podem dar sustentação econômica e simbólica à existência dos Atikum e da população de Conceição das Crioulas.

Apesar da política partidária ter deflagrado, em 2000, um processo de demandas identitárias diferentes do que vinha se colocando, há necessidade de se atentar para outros fatores que compõem o contexto Atikum/Crioulas.

Primeiramente, não havia uma política de assistência específica para a população quilombola, o que fez com que as terras de Conceição das Crioulas continuassem, mesmo depois de sua titulação, sob o controle dos fazendeiros, ao contrário do que ocorre na Terra Indígena Atikum, posto que, naquele momento, os índios reivindicavam a liberação dos recursos para a indenização das benfeitorias dos imóveis incidentes e já existia todo um corpo normativo que lhes garantiam acesso a programas diferenciados na área de saúde e de educação.

Em segundo lugar, o atendimento da Fundação Nacional de Saúde (Funasa $)^{9}$, dirigido especificamente para os indígenas, havia se constituído como um elemento de disputa e um canal de agenciamento da identidade étnica entre alguns sítios, como os de Massapê, Rodeador e Paus Brancos.

Como terceiro fator, podemos dizer que havia certa recorrência por parte da população em geral a representantes Atikum e ao Posto Indígena da Fundação Nacional do índio, FUNAI para a solicitação de atestado da

\footnotetext{
${ }^{9}$ A partir de 2009, o subsistema de atenção á saúde indígena fica a cargo da SESAI, Secretaria Especial de Saúde Indígenas e implementado pelos Distritos Sanitários Especiais Indígenas, DESEIs.
} 
identidade indígena (declaração formal da FUNAI, cuja responsabilidade é, geralmente, compartilhada com alguma liderança indígena, que também assina o documento), a fim de assegurar a concessão de aposentadoria pelo Instituto Nacional do Seguro Social, INSS, já que aos índios são garantidos todos os direitos de qualquer beneficiário da Previdência Social.

Por último, há de se destacar que a região em que se encontram esses dois territórios é conhecida pelo plantio de maconha, que, constituindo uma prática ilegal, acaba por estruturar uma rede de poder paralelo, difícil de transpor, devido às ameaças dos que controlam as plantações.

Foi em meio a este contexto que, em 12 de dezembro de 2004, as ameaças de violência se concretizaram a partir de uma tentativa de incêndio da sede da Associação Quilombola de Conceição das Crioulas, AQCC, por meio de dispersão de gasolina ao seu redor. As táticas utilizadas são descritas nos documentos elaborados pelas lideranças quilombolas para conclamar as autoridades a tomar alguma providência. A preocupação reside no fato de que a ofensiva não se restringiu apenas ao patrimônio físico da AQCC, mas também atentava contra a vida de lideranças, que se revezam nos pernoites na sede a fim de garantir a segurança da mesma. Além do atentado à vida das lideranças quilombolas, houve a suspensão do fornecimento de energia elétrica para um povoado de 150 famílias no momento em que o incêndio foi provocado. Ou seja, tratava-se da tentativa de calar a voz das lideranças e também de intimidar a população quilombola de maneira geral, com a demonstração do poderio que sempre caracterizou as relações no sertão nordestino. A ocasião em que esse fato aconteceu também deve ser destacada.

Em 2004, o INCRA havia finalmente iniciado o processo de georreferenciamento e de levantamento fundiário da terra quilombola. $\mathrm{O}$ que antes era apenas uma possibilidade passa a se efetivar com a identificação das benfeitorias a serem indenizadas e com a classificação dos ocupantes que não são quilombolas. O caráter belicoso dos ocupantes da área quilombola é descrito nos documentos elaborados pela AQCC e foi demonstrado em todas as ocasiões em que houve confronto com os quilombolas. Considerando o que tem se configurado no plano das disputas territoriais no nordeste brasileiro e tendo ainda como referência as dificuldades que historicamente as populações 
tradicionais têm enfrentado para assegurar seus direitos constitucionais, podemos entender esse momento vivenciado pela comunidade de Conceição das Crioulas como facilmente previsível. Há, porém, a necessidade de se salientar a desconsideração por parte do poder público para reconduzir suas ações e minimizar as tensões latentes mesmo diante dessas previsões.

No caso do processo de regularização das terras quilombolas, a lentidão na sua normatização e a falta de definição de uma série de procedimentos e competências básicas para o trato da questão provocaram a constituição de uma fenda institucional que foi sendo preenchida por mecanismos elaborados no plano local por agências e atores sociais que se encontram inseridos num contexto bem mais complexo que a mera polarização entre sociedade nacional e populações tradicionais.

Menos de dois meses após o incidente relatado que pôs em risco a sede da Associação Quilombola e que evidencia as ameaças de morte que as lideranças vêm sofrendo, outro evento se destaca naquele contexto. A "investida de fazendeiros em Conceição das Crioulas" no dia 12 de fevereiro de 2005, segundo o relato da AQCC, veio, mais uma vez, articulada com argumentos que procuravam explicar as disputas territoriais naquela região como sendo uma contenda entre indígenas e quilombolas.

Do ponto de vista das políticas públicas, essa tensão tem se firmado através das propostas de redefinição dos limites da Terra Indígena Atikum e consequente diminuição do território de Conceição das Crioulas, do cadastramento de moradores dos sítios quilombolas como indígenas visando o acesso aos programas da FUNASA e da classificação de escolas, presentes no território quilombola, como indígenas.

Associados a esses argumentos, também foi constituída uma disputa em relação aos bens simbólicos das comunidades ali envolvidas; estes bens vinham sendo manipulados estrategicamente por diversos sujeitos, que nem indígenas, nem quilombolas, mas eram interessados na apropriação daquelas terras. Apesar das relações de parentesco claramente presentes entre os Atikum e os quilombolas, para efeito de delimitação das categorias administrativas e legais que lhes conferem direitos 
diferenciados, foi colocado como ordem do dia que "onde se dança o toré é área indígena", atribuindo um caráter substancializado às manifestações culturais e criando novas possibilidades de clivagens e tensões.

O relato da AQCC (datado de 13.02.05) afirmava que:

Uma ação dos fazendeiros Simão David, Juvenal Pereira e Maria Eruça de Sá (Bebé), foi realizar um “Toré” que aconteceu nesse dia 12 de fevereiro na Vila de Conceição das Crioulas [localidade que concentra as articulações políticas e sociais da comunidade quilombola] o qual serviu apenas para acirrar ainda mais os conflitos entre quilombolas e fazendeiros.

As tensões aumentam, não pelo ritual, pois sabemos das ligações fortes que temos como povo Indígena Atikum, mas pela audácia dos fazendeiros em não permitirem que jovens quilombolas da comunidade ouvissem som na sua própria casa [o que atrapalharia a manifestação do toré], chegando a invadir a residência dos Jovens Juciê Josémembro da coordenação da AQCC e Adalmir José, seu irmão, também liderança jovem e monitor do Programa de Erradicação do Trabalho Infantil na comunidade e componente da comissão de juventude da AQCC.

O documento acima referido, divulgado na rede de apoio ao movimento quilombola em Pernambuco, acrescentou que a ação agressiva foi liderada por Donato Galdino dos Santos (Dão de Lolô), sobrinho de Simão David, e acompanhada pelos vereadores de Salgueiro, Ayres de Sá Carvalho Jr (PSB) - presidente da Câmara de Vereadores de Salgueiro e o Professor Antenor Filho (PL), também membro da mesa Diretora da referida Casa.

Com o relato, há de se atentar para o fato de que os conflitos são, principalmente, resultantes da ausência de políticas públicas ou da incapacidade do Estado de lidar com os jogos classificatórios que envolvem o poder nos mais diferentes níveis, presentes em todos os contextos da realidade social. 


\section{Censos, classificações e estratégias técnico-burocráticas}

Rememorar esses eventos possibilita visualizar que tratar de reconhecimentos de direitos e correlatos processos de reconhecimento territorial é provocar elementos citados no início deste artigo: o caminho da governança está posto como uma questão menos do político e mais das políticas administrativas, permeada pela cultura política que impera na estrutura de Estado.

Nos primeiros meses de 2016, enfrentamos o desmonte do Estado e nos deparamos com uma onda conservadora que retoma o que Avritzer (1995) afirmava para a década de 80 passada sobre as características do funcionamento da democracia brasileira. $\mathrm{O}$ autor chamava atenção para: (a) persistência de um comportamento não-democrático das elites políticas, que continuavam seguindo estratégias patrimonialistas e corporativistas; (b) a dissociação entre práticas políticas democráticas no nível da institucionalidade política e a persistência de práticas nãodemocráticas no nível micro; e (c) a não aceitação da cidadania civil e social que se traduzira na rejeição ou desconhecimento dos avanços constitucionais nesse campo, assim como na impossibilidade de um pacto social (AVRITZER, 1995, p. 109). Esse mesmo autor ainda enfatiza que o problema da democracia não se reduz somente à questão do funcionamento adequado das instituições políticas, mas se liga também às práticas dos aparelhos de Estado e às suas relações com os atores sociais.

Seja pelo aparato legal, seja pelas práticas de não reconhecimento das diversas vozes que ecoam das mobilizações sociais, o Estado brasileiro dá mostras de ser um jovem ranzinza que sofre de doença crônicodegenerativa e definha.

As esferas de negociação, que começaram a se estruturar a partir da primeira gestão do governo Lula, não foram suficientes para garantir que o Estado interagisse com membros da sociedade civil em suas capacidades individuais ou coletivas. Os ranços da arcaica estrutura de poder no Brasil teimam em negar o caráter moral de comunidade que os grupos populacionais (nos quais estão engendradas as criativas formas de mobilização e agenciamento políticos dos povos e comunidades tradicionais) acionam. 
Neste campo multifacetado e difuso, procuramos identificar eventos, situações e agências que poderiam ajudar a compor o que vem se desenhando como o da política de reconhecimento de direitos das comunidades quilombolas. Longe de ter apresentado uma etnografia no seu sentido mais clássico, mas de ter na experiência etnográfica se inspirado, a intenção é também mostrar que o estudo de eventos contínuos e processos refletem o dinamismo das relações de poder e permitem questionar o papel e os limites do Estado na atualidade e a importância das estruturas de poder formais e informais.

\section{A surdez do Estado: algumas considerações para final de conversa}

A Constituição de 1988 e seu processo constituinte, inegavelmente, constituem um marco na conformação da democracia no Brasil e nos novos espaços que determinadas parcelas passam a ocupar.

Apresentar tais mudanças como resultado das transformações ocorridas no plano do discurso oficial, institucional, aponta para uma percepção bastante reducionista da capacidade de ação dos atores sociais; daí a necessidade de atentarmos para algumas características de como tem se dado a ação coletiva de algumas parcelas sociais no sentido de participar efetivamente de esferas públicas de negociação e, através destas mobilizações, de se fazerem plenamente reconhecidas. Muitas vezes, são ações que parecem fragmentadas em diversas formas de unidades de mobilização, que assumem a nominação de uma lógica de classificação impositiva, mas que, articuladas, compõem o que entendemos como as esferas de negociação para a possível construção de uma sociedade plural.

Mesmo tratando-se, como afirma Burity (2002), de organizações pequenas, e com um raio de abrangência que não vai além dos limites estaduais, percebe-se facilmente o emaranhado de vínculos nos contextos de demandas dos direitos quilombolas, que ora são instrumentais, ora baseados em convergências de princípios, ora em ambos, e são ditados por necessidade urgentes e por contingências (oportunidades, pressões, demandas de outros atores, habilidades de alguns de seus participantes). 
A necessidade urgente das unidades de mobilização que se afirmam como quilombolas é o confronto com um modelo universalista de sociedade que se baseia na privatização das terras, na negação de direitos coletivos e do reconhecimento das especificidades socioculturais.

\section{Referências}

AIRES, Nice Machado. Nice Guerreira: mulher, quilombola e extrativista da floresta. AIRES, Nice, VALLE, Camila do; MARTINS, Cynthia; NUNES, Patrícia (orgs.). ALMEIDA, Alfredo Wagner Berno de. Rio de Janeiro: Casa 8, 2016.

ALMEIDA, A.W. Terras tradicionalmente ocupadas: processo de territorialização, movimentos sociais e uso comum. In: Terras de quilombos, terras indígenas, "babaçuais livres", "castanhais do povo", faxinais e fundos de pasto: terras tradicionalmente ocupadas. Manaus: PPGSCA-UFAM, 2006. p. 21-99.

ALMEIDA, A. W. B. Quilombos: temas e problemas.'In: ALMEIDA, A. W. B. Quilombos e as novas etnias. Manaus: UEA Edições, 2011, p.47-55.

ALMEIDA, A. W. B. Quilombolas e as novas etnias. Manaus: UEA Edições, 2011

ANTUNES, M. O. A terra que volta: gerindo territórios, memórias, conflitos e normas em Conceição das Crioulas. 2016. 455 p. Rio de Janeiro. Programa de Pós-Graduação em Antropologia Social do Museu Nacional/UFRJ, 2016.

AVRITZER, Leonardo. "Cultura política, atores sociais e democratização: uma crítica às teorias da transição para a democracia". Revista Brasileira de Ciências Sociais, 28, JUN, 1995.

BURITY, J. S., CAVALCANTI, H. Um novo espaço público entre os pobres? Identidade coletiva e associativismo local no Nordeste brasileiro. In: BURITY, J.S. Polifonia da miséria: uma construção de novos ohares. Recife: Editora Massangana, 2002. p. 311-334.

CHATTERJEE, P. Três caminhos para a democracia radical. Lua Nova, São Paulo, 169-189. 2013. 
CUNHA Fo , C. M. A construção do Estado Plurinacional na Bolívia: institucionalizando o abigarrado sem homogeneização modernizadora? Anais XV CISO - Encontro de Ciências Sociais do Norte e Nordeste. Teresina/PI, 2012.

FAJARDO, R. Y. Aos 20 anos da Convenção 169 da OIT: balanço e desafios da implementação dos direitos dos Povos Indígenas na América Latina. In: VERDUM, Ricardo. Povos Indígenas: constituições e reformas políticas na América Latina. Brasília: Instituto de Estudos socioeconômicos, 2009. p. 9-62.

FIALHO, V. Informes 1 sobre Conceição das Crioulas 1 (Dezembro de 2004/ janeiro de 2005) e Informe 2 (Fevereiro de 2005). Monitoramento - Observatório Quilombola, KOINONIA. Disponível em: <http://www.koinonia.org.br/oq/info_conceicao.htm $\geq$. Acesso em 27 mar 2006.

FIALHO, V. Tensões e dinâmicas territoriais: povos e comunidades tradicionais no contexto do desenvolvimento de Pernambuco. Raízes, v. 31, p. 111, 2011.

FRASER, N. Justicia interrupta: reflexiones críticas desde la posicion 'postsocialista'. Bogotá: Universidad de los Andes. 1997.

PIRAUX, M. Dinâmicas territoriais, definição e análise. In:

Diversificação dos espaços rurais e dinâmicas territoriais no nordeste do Brasil. João Pessoa: Zarinha Centro de Cultura, 2009. p.31-54.

UFFORD, P. Q. V. "Knowledge and ignorance in the practices of development policy" In: M. Hobart, An Anthropological Critique of Development: the growth of ignorance. London /New York, Routledge, 1997.

VIANNA JR, A. Terra, territórios e conhecimento tradicional espacial. Cadernos de debates Nova Cartografia Social: conhecimentos tradicionais ma Pan-Amazônia. v. 1, n. 1. Manaus: Projeto Nova Cartografia Social da Amazônia/UEA Edições, 2010.2.

Recebido em 25/05/2016

Aprovado em 30/06/2016 